\begin{tabular}{|c|l|}
\hline Title & $\begin{array}{l}\text { Development of T aenia saginata asiatica metacestodes in SCID mice and its infectivity in human and al ternative } \\
\text { definitive hosts }\end{array}$ \\
\hline Author(s) & Chang, S. L.; Nonaka, N.; Kamiya, M.; Kanai, Y.; Ooi, H. K.; Chung, W. C.; Oku, Y. \\
\hline Citation & $\begin{array}{l}\text { Parasitology Research, 96/2), 95-101 } \\
\text { https://doi.org/_0.1007/300436-005-1328-4 }\end{array}$ \\
\hline Issue Date & 2005-05 \\
\hline Doc URL & http://hdl.handle.net/2115/765 \\
\hline Rights & The original publication is available at www.springerlink.com \\
\hline Type & article (author version) \\
\hline File Information & ParasitolRes96_p95.pdf \\
\hline
\end{tabular}

Instructions for use 
S. L. Chang, N. Nonaka, M. Kamiya, Y. Kanai, H. K. Ooi, W. C. Chung, Y. Oku

\title{
Development of Taenia saginata asiatica metacestodes in SCID mice and its infectivity in human and alternative definitive hosts
}

\author{
S. L. Chang, N. Nonaka, Y. Kanai, Y. Oku (Corresponding author) \\ Laboratory of Parasitology, Graduate School of Veterinary Medicine, Hokkaido University, Sapporo \\ 060-0818, Japan. \\ E-mail address: oku@vetmed.hokudai.ac.jp \\ Tel. and fax:+81-11-706-5196
}

M. Kamiya

Laboratory of Environmental Zoology, Department of Biosphere and Environmental Sciences, Faculty of Environmental Systems, Rakuno Gakuen University, Ebetsu 069-8501, Japan

H. K. Ooi

Department of Veterinary Medicine, National Chung Hsing University, 250 Kuo Kuang Road, Taiwan

W. C. Chung

Department of Parasitology, Taipei Medical University, 250 Wu Hsing Road, Taipei, Taiwan

\begin{abstract}
Development of Taenia saginata asiatica metacestodes in SCID mice and its infectivity in humans, and in golden hamsters and Mongolian gerbils as alternative definitive hosts, were investigated. Cysticerci were recovered from SCID mice that were subcutaneously injected with hatched eggs of $T$. s. asiatica. The morphological changes of cysticerci were observed. The recovered cysticerci were by fed to gerbils, hamsters and humans, to check for infectivity. Tapeworms were recovered from gerbils and hamsters that were fed 20 to 45 week-old cysticerci, and proglottids excretion were observed in human volunteers fed with 45 week-old cysticerci. However, no tapeworms were recovered from gerbils fed with 10 week-old cysticerci. Our results suggest that $T$. s. asiatica oncospheres needed more than 20 weeks to develop to maturity in SCID mice to be infective to both their natural and alternative definitive hosts.
\end{abstract}

Keywords: Taenia saginata asiatica; Metacestode; Cysticercus; SCID mice; Alternative host; Human infection 


\section{Introduction}

Asian taeniasis, caused by Taenia saginata asiatica, was first reported by Oi in 1915 in central Taiwan (Oi 1915). It has been reported in many other Asian countries such as China (several provinces), Korea, Indonesia, Thailand, Philippines, Malaysia and Myanmar (Fan et al. 1989, 1990a, 1992a, 1992b; Eom and Rim 1993; Bowles and McManus 1994; Simanjuntak et al. 1997; Zhang et al. 1999; Fan 2000; Fan et al. 2001; Eom et al. 2002; Ito et al. 2003).

Compared with other human taeniids, the tapeworm of $T$. s. asiatica has no hook on its rostellum, which differed from T. solium but is similar to the classical T. saginata (Taenia saginata saginata) (Fan et al. 1995). However, in the intermediate host, metacestodes of T. s. asiatica parasitize in the viscera (mostly in the liver) of pigs (Fan et al. 1995; Eom and Rim 2001), whereas T. s. saginata parasitize in the muscle of cattle (Schmidt and Roberts 2000).

Recently, eggs of T. s. asiatica had been reported to develop into mature cysticerci when injected into the subcutaneous tissue of severe combined immunodeficiency (SCID) and immunosuppressed ICR mice (Ito et al. 1997b; Ito and Ito 1999; Wang et al. 1999). The size of the cysticerci recovered from SCID mice was found to be larger than those in the pigs (Ito et al. 1997a). Moreover, 49\% of the metacestode were seen to be calcified or degenerated in 34 infected pigs at 11 to 97 days post-infection but no calcification of the metacestodes was observed in the SCID mice at 244 days post-infection (Wang et al. 2000; Fan et al. 1990c).

Since the SCID mouse has proved to be an experimental intermediate host model for the study of the development of $T$. s. asiatica metacestodes, it is necessary to confirm the infectivity of the cysticerci recovered from SCID mice. Human is the only known natural definitive host of the three aforementioned human taeniids. In addition, alternative definitive hosts have been used to test for the infectivity of the cysticerci. Alternative definitive host models for T. solium using golden hamsters, Mongolian gerbils, chinchillas and gibbons that were orally inoculated with cysticerci obtained from naturally infected pigs, have been reported. Gravid proglottids were recovered only from chinchillas and gibbons (Cadigan et al. 1967; Verster 1971, 1974; Maravilla et al. 1998). For T. s. saginata, sexually mature tapeworms were recovered from gerbils inoculated with cysticerci from naturally infected cattle (Kamiya et al. 1990). It has also been demonstrated that cysticerci of $T$. solium recovered from SCID mice could develop to maturity in hamster albeit only pregravid tapeworm was observed (Wang et al. 1999). In the present study, we examined the infectivity and development of $T$. s. asiatica metacestodes from SCID mice in human and its alternative definitive hosts, the golden hamsters and Mongolian gerbils. 


\section{Materials and Methods}

Parasite

Proglottids of T. s. asiatica adult worm were collected from a Taiwanese aborigine patient after deworming with atabrine (Quinacrine) (Fan et al. 1990b). The worms were kept at $4^{\circ} \mathrm{C}$ in saline until used.

Development of metacestodes in SCID mice

Eggs were collected from gravid proglottids. Embryophores were removed by incubating the eggs in $10 \%$ sodium hypochlorite for 10 minutes, and the oncospheres were washed 5 times in sterile saline. Eighteen SCID mice (C.B-17/Icr-scidJcl, female) purchased from a commercial source (CLEA, Tokyo, Japan) were subcutaneously inoculated with 20,000 and 40,000 oncospheres and intraperitoneally with 18,600 oncospheres of $T$. s. asiatica, respectively (Table 1). The SCID mice were kept in sterile cages and wood chips used as bedding. The mice were provided with autoclaved drinking water and commercial pellet food (CLEA, Tokyo, Japan) ad libitum. All the inoculated SCID mice were sacrificed under ethyl ether anaesthesia at 10, 20, 21, 24 and 45 weeks after inoculation. To check the evagination rate, cysticerci were incubated in calf bile in $37^{\circ} \mathrm{C}$ for 1 hour. For morphological observation, evaginated cysticerci were relaxed in the refrigerator $\left(4^{\circ} \mathrm{C}\right)$ in saline overnight, fixed in 70\% alcohol and cleared in glycerin. 
Table 1 Recovery rates of T. s. asiatica metacestodes from eighteen SCID mice subcutaneously inoculated with oncospheres

\begin{tabular}{|c|c|c|c|c|c|c|c|}
\hline \multicolumn{3}{|c|}{ Oncospheres } & \multicolumn{2}{|c|}{ SCID Mice } & \multicolumn{3}{|c|}{ Metacestodes recovery } \\
\hline \multirow[t]{2}{*}{ Source $^{\mathrm{a}}$} & \multirow{2}{*}{$\begin{array}{c}\text { Inoculation } \\
\text { route }\end{array}$} & \multirow{2}{*}{$\begin{array}{c}\text { Inoculation } \\
\text { dose }\end{array}$} & \multirow[t]{2}{*}{ Number } & \multirow{2}{*}{$\begin{array}{l}\text { Age of } \\
\text { autopsy } \\
\text { (weeks) }\end{array}$} & \multicolumn{2}{|c|}{ Number } & \multirow{2}{*}{$\begin{array}{c}\text { Recovery } \\
\text { rate (\%) }\end{array}$} \\
\hline & & & & & Average & Range & \\
\hline \multirow[t]{2}{*}{ A } & Subcutaneous & 20,000 & 5 & 12,20 & 133.6 & $20-218$ & 0.1-1.1 \\
\hline & Intraperitoneal & 18,600 & 5 & 12,20 & 10.8 & $0-50$ & $0-0.3$ \\
\hline \multirow[t]{2}{*}{$\mathrm{B}$} & Subcutaneous & 40,000 & 3 & 24,62 & 153.6 & $1-450$ & $0.003-1.1$ \\
\hline & Subcutaneous & 20,000 & 5 & $10-45$ & 814.2 & $174-2,000^{b}$ & $0.9-6.4$ \\
\hline
\end{tabular}

a Source A: Eggs collected from worms after deworm treatment in December, 2003 and inoculated into mice on January 9, 2004.

a Source B: Eggs collected from worms after deworm treatment in April, 2004 and inoculated in May, 2004.

${ }^{\mathrm{b}}$ The number of recovered metacestodes from 1 (2000 metacestodes were recovered) of the 5 mice was estimated by the dilution method, and the other samples were counted without diluting.

Development of tapeworms in human and alternative definitive hosts

Three human volunteers (1 female, volunteer A; age 30, 2 males, volunteer B and volunteer C; age 26 and 51 years old) each swallowed five 45-week-old cysticerci that were obtained from the SCID mice. After eating the cysticerci, the human volunteers checked their feces daily for the presence of proglottids. Fifty-five 3-week-old male golden hamsters were purchased from a commercial breeder (SLC, Shizuoka, Japan) and used for the experiment after 3 weeks acclimatization (Table 2). The hamsters were divided into 2 groups, designated $\mathrm{H} 1$ and H2, and then orally inoculated with 20 or 24 week-old cysticerci, respectively. Eighty-one 5 to 11 week-old male and female Mongolian gerbils raised in our laboratory, were used for the experiment (Table 2). The gerbils were orally inoculated with 10, 20, 21 and 45 week-old cysticerci and divided into 4 groups, namely G1, G2, G3 and G4. The animals were injected subcutaneously with prednisolone acetate at different schedules as shown in Table 2. They were then orally inoculated with cysticerci of $T$. $s$. asiatica obtained from the SCID mice by stomach tubes and fed commercial pellet food (CLEA, Tokyo, Japan) and water ad libitum. Animals were sacrificed under ethyl ether anaesthesia at 2 to 146 days post inoculation (DPI) and tapeworms were collected from their intestines. After relaxing the worm in saline at $4^{\circ} \mathrm{C}$ overnight, the worms were fixed in $70 \%$ ethanol, stained with acid-carmine and observed under light microscope. 
Table 2

Alternative definitive host groups and their treatment

\begin{tabular}{|c|c|c|c|c|c|c|}
\hline \multicolumn{4}{|c|}{ Animals } & \multicolumn{2}{|c|}{ Cysticerci } & \multirow{2}{*}{$\begin{array}{c}\text { Schedule of PA } \\
\text { treatment }^{\mathrm{c}}\end{array}$} \\
\hline Group & Number & Age (weeks old) & $\operatorname{Sex}^{\mathrm{a}}$ & Number ${ }^{\mathrm{b}}$ & Age (weeks old) & \\
\hline \multirow[t]{4}{*}{ H1 } & 10 & 6 & $M$ & 6 & 20 & $\mathrm{~A}$ \\
\hline & 10 & 6 & M & 6 & 20 & B \\
\hline & 11 & 6 & M & 6 & 20 & $\mathrm{C}$ \\
\hline & 10 & 6 & M & 6 & 20 & $\mathrm{D}$ \\
\hline \multirow[t]{2}{*}{$\mathrm{H} 2$} & 8 & 6 & $\mathrm{M}$ & 15 & 24 & A \\
\hline & 6 & 6 & M & 15 & 24 & $\mathrm{D}$ \\
\hline G1 & 21 & $5-7$ & $\mathrm{M}, \mathrm{F}$ & $20-40$ & 10 & A \\
\hline \multirow[t]{3}{*}{$\mathrm{G} 2$} & 11 & $6-9$ & $\mathrm{M}, \mathrm{F}$ & 6 & 20 & A \\
\hline & 11 & $6-9$ & $\mathrm{M}, \mathrm{F}$ & 6 & 20 & $\mathrm{C}$ \\
\hline & 10 & $6-9$ & M & 6 & 20 & $\mathrm{D}$ \\
\hline G3 & 11 & $6-12$ & M & $25-40$ & 21 & A \\
\hline \multirow[t]{2}{*}{ G4 } & 11 & $6-11$ & M & 2 & 45 & $\mathrm{E}$ \\
\hline & 6 & 5 & M & 2 & 45 & $\mathrm{E}$ \\
\hline
\end{tabular}

${ }^{\text {a }} \mathrm{M}$ : male; F: female.

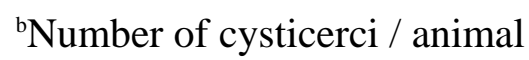

'Dosage of PA (prednisolone acetate) was 0.2-0.5 mg per animal. PA treatment schedules are as follows.

A: every 7 days from 17-3 days before infection;

B: every 4 days from 6 days before infection;

C: every 2 days from 6 days before infection;

D: no PA treatment;

E: every 7 days from 7-0 days before infection and every 14 days from 56 days after infection.

\section{Results}

Development of metacestodes in SCID mice

Metacestodes were recovered from the subcutaneous tissue inoculation site as well as from the peritoneal cavity of SCID mice (Table 1). The recovery rates of metacestodes from intraperitoneally inoculated mice ranged from 0 to $0.3 \%$, while those from subcutaneously inoculated mice ranged from 0.1 to $1.1 \%$ (Table 1 , parasite source $\mathrm{A}$ ). The recovery rate of metacestodes from the 
subcutaneously inoculated mice was higher than those from the intraperitoneally inoculated mice.

Evagination rate of the recovered cysticerci was $88 \%$ for 10 week-old cysticerci, $69 \%$ for 24 week-old cysticerci and $100 \%$ for 45 week-old cysticerci (Table 3). The total length of the evaginated cysticerci increased with age, as well as the average width of the scolex and diameter of the suckers (Table 3).

Microscopic observation revealed that calcareous corpuscles were few in 10 week-old cysticerci but abundant in 24 and 45 week-old cysticerci (Fig. 1b, 2b). Hooklets (rudimentary hooks) could be observed in 10 (Fig. 1c-d), 24 (Fig. 2c-d) and 45 week-old metacestodes (10-48\% of the specimens all ages possess the hooklets). The rostellar region of 10 week-old cysticerci was full of small-granules aggregations (Fig. 1c-d), while the rostellar regions of 24 and 45 week-old cysticerci showed fewer small-granules aggregations (Table 3, Fig. 2c-d).

The recovery rate of tapeworms was 1.2\% (3/246) for 20 week-old and 1.4\% (3/210) for 24 week-old cysticerci in the golden hamster. The recovery rate of tapeworm was $0 \%(0 / 640)$ for 10 week-old, 1.0\% (2/192) for 20 week-old, 0.5\% (2/403) for 21 week-old and 5.8\%(2/34) for 45 week-old cysticerci in Mongolian gerbils (Table 4).

\section{Table 3}

Evagination rates and morphological measurements of $T$. s. asiatica cysticerci recovered from the three SCID mice

\begin{tabular}{ccccccc}
\hline \multirow{2}{*}{$\begin{array}{c}\text { Age of } \\
\text { metacestodes } \\
\text { (weeks) }\end{array}$} & \multicolumn{5}{c}{ Morphological observation of cysticerci } & Evagination \\
\cline { 2 - 5 } & Number of & $\begin{array}{c}\text { Total length } \\
\text { examined }\end{array}$ & $\begin{array}{c}\text { Width of scolex } \\
(\mu \mathrm{m})\end{array}$ & $\begin{array}{c}\text { Diameter of } \\
(\mu \mathrm{m})\end{array}$ & $\begin{array}{c}\text { No. of calcareous } \\
\text { suckers }(\mu \mathrm{m})\end{array}$ & rate $^{\text {a }}$ \\
corpuscles & \\
\hline 10 & $\mathrm{~N}=24$ & $1,750 \pm 470$ & $590 \pm 130$ & $220 \pm 60$ & Few (less than 50) & $50 / 57(88 \%)$ \\
24 & $\mathrm{~N}=30$ & $3,890 \pm 800$ & $680 \pm 100$ & $290 \pm 30$ & Abundant & $34 / 49(69 \%)$ \\
45 & $\mathrm{~N}=19$ & $5,930 \pm 870$ & $710 \pm 60$ & $300 \pm 40$ & Abundant & $25 / 25(100 \%)$ \\
\hline
\end{tabular}

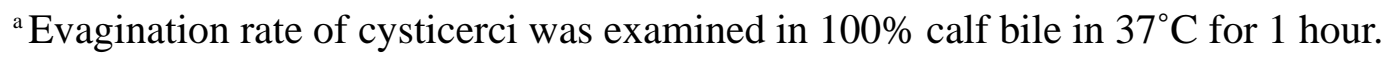

Development of tapeworms in alternative definitive hosts 
Table 4

Recovery of T. s. asiatica tapeworms from Mongolia gerbils and golden hamsters orally inoculated with cysticerci obtained from SCID mice

\begin{tabular}{|c|c|c|c|c|c|c|c|c|}
\hline \multirow{2}{*}{$\begin{array}{c}\text { Animal } \\
\text { Group }\end{array}$} & \multicolumn{2}{|c|}{$\begin{array}{l}\text { Cysticerci } \\
\text { inoculated }\end{array}$} & \multicolumn{5}{|c|}{ Weeks post-infection at necropsy } & \multirow{2}{*}{$\begin{array}{c}\text { Tapeworms } \\
\text { recovery } \\
\text { Number }^{c}(\%)\end{array}$} \\
\hline & Age (wk) & Number $^{\mathrm{a}}$ & $<1$ week & 1-2 weeks & 2-4 weeks & $>4$ weeks & Total number ${ }^{\mathrm{b}}(\%)$ & \\
\hline $\mathrm{H} 1$ & 20 & 6 & $0 / 16^{d}$ & $2 / 12$ & $1 / 13$ & - & $3 / 41(7)$ & $3 / 246(1.2)$ \\
\hline $\mathrm{H} 2$ & 24 & 15 & $1 / 1$ & $1 / 1$ & $1 / 6$ & $0 / 6$ & $3 / 14(21)$ & 3/210 (1.4) \\
\hline G1 & 10 & 20,40 & - & $0 / 21$ & - & - & 0/21 (0) & 0/640 (0) \\
\hline G2 & 20 & 6 & $1 / 12$ & $1 / 7$ & $0 / 13$ & - & 2/32 (6) & $2 / 192(1.0)$ \\
\hline G3 & 21 & $25-40$ & $0 / 1$ & $1 / 3$ & $1 / 3$ & $0 / 4$ & 2/11 (18) & $2 / 403(0.5)$ \\
\hline G4 & 45 & 2 & $0 / 2$ & $0 / 1$ & - & $2 / 14$ & 2/17 (11) & 2/34 (5.8) \\
\hline
\end{tabular}

${ }^{\text {a }}$ Number of inoculated cysticerci / animal

${ }^{\mathrm{b}}$ Only one worm was detected in each infected host

c The number of tapeworms recovered from hamsters or gerbils / the number of cysticerci inoculated.

${ }^{d}$ No. of positive animal / No. of examined. 

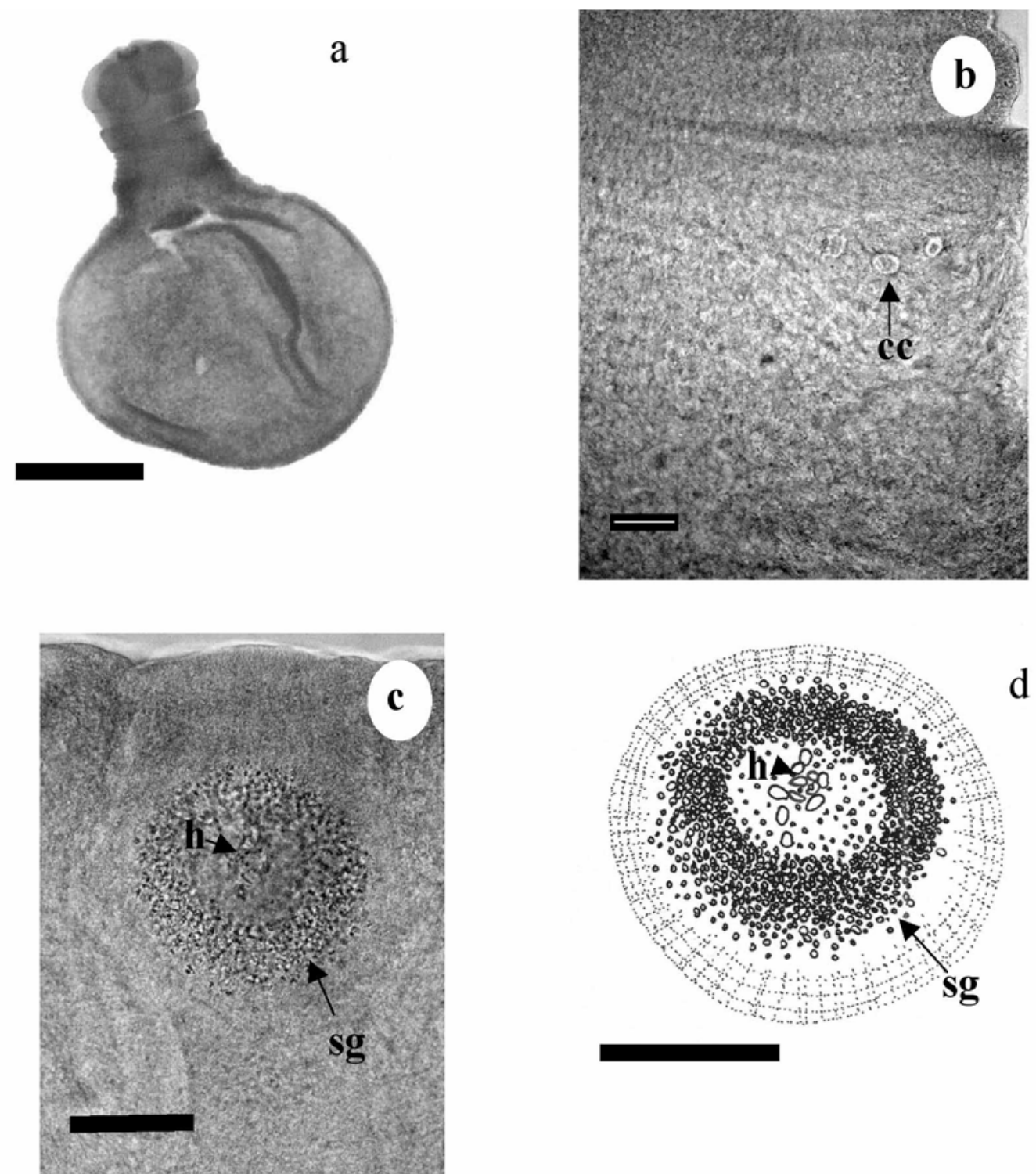

Fig. 1a-d 10 week-old cysticerci recovered from SCID mice. a A whole specimen. Bar, $500 \mu \mathrm{m}$. b Few calcareous corpuscles (cc). Bar, $50 \mu \mathrm{m}$. c The rostellum. Bar, $50 \mu \mathrm{m}$. Hooklets (h) and small-granules aggregations (sg). Bar, $50 \mu \mathrm{m}$. d Drawing of the rostellum in the Fig.1c. 

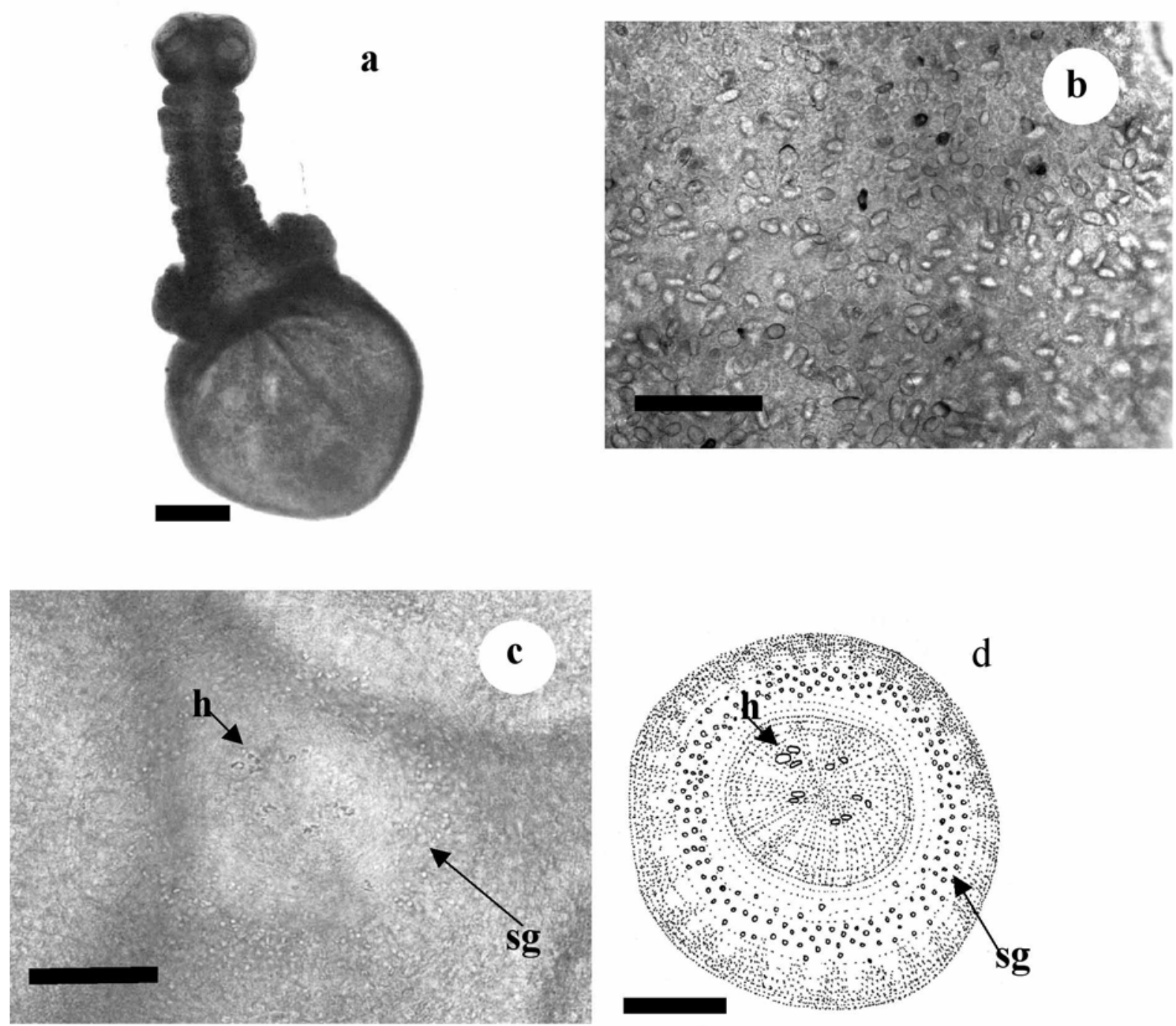

Fig. 2a-d A 24 week-old metacestode recovered from SCID mice. Bar, $500 \mu \mathrm{m}$. a A whole specimen. Bar, $500 \mu \mathrm{m}$. b Calcareous corpuscles completely filled the neck region of the metacestode. Bar, $50 \mu \mathrm{m}$. c The rostellum. Bar, $50 \mu \mathrm{m}$. d Drawing of the rostellum in the Fig.1-B. Hooklets (h) and small-granules aggregations (sg). Bar, $50 \mu \mathrm{m}$. 
Development of tapeworms in alternative definitive hosts

Tapeworms of T. s. asiatica were recovered from golden hamsters at days 6, 7, 12, 13 and 14 post-infection. The worms were also recovered from immunosuppressed gerbils at days 2, 7, 25, 36 and 62 post-infection (Table 4). Worms were detected in the anterior part of the small intestine. The length of the six tapeworms recovered from six hamsters (one worm from each animal) after fixation, ranged from 1 to $6 \mathrm{~mm}$, while that of the six tapeworms from six gerbils ranged from 1 to $40 \mathrm{~mm}$ (Fig. 4). The tapeworm positive rate of the hamsters inoculated with 20 week-old cysticerci was 7\% (3/41) and with 24 week-old cysticerci was 21\% (3/14). The tapeworm positive rate of the gerbils inoculated with 10 week-old cysticerci was $0 \%(0 / 21)$, with 20 week-old cysticerci in gerbils was $6 \%$ (2/32), with 21 week-old cysticerci was 18\% (2/11), and with 45 week-old cysticerci in gerbils was 11\% (2/17) (Table 4). Genital primordia were observed in posterior segments of the worms recovered from the gerbils on days 36 and 62 post-infection (Fig. 3). The longest worm (40 $\mathrm{mm}$ in total length) with 164 demarcated segments was recovered from a gerbil at 36 DPI.

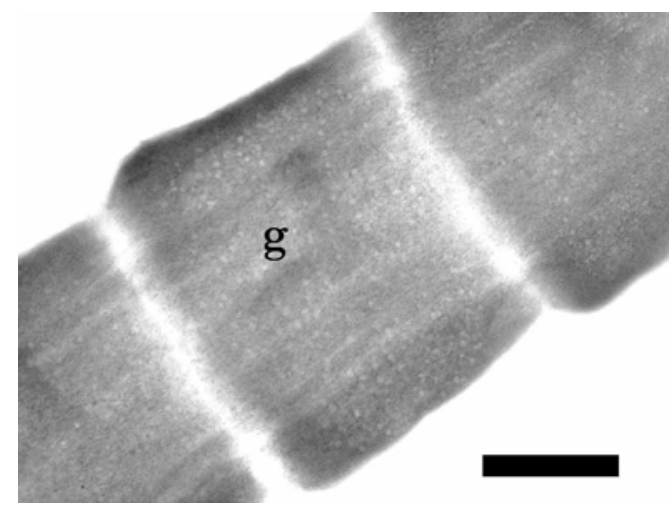

Fig. 3 Tapeworm of T. s. asiatica recovered from a gerbil at day 36 post-infection. Genital primordia (g) in posterior segment of the strobila. Bar, $200 \mu \mathrm{m}$. 


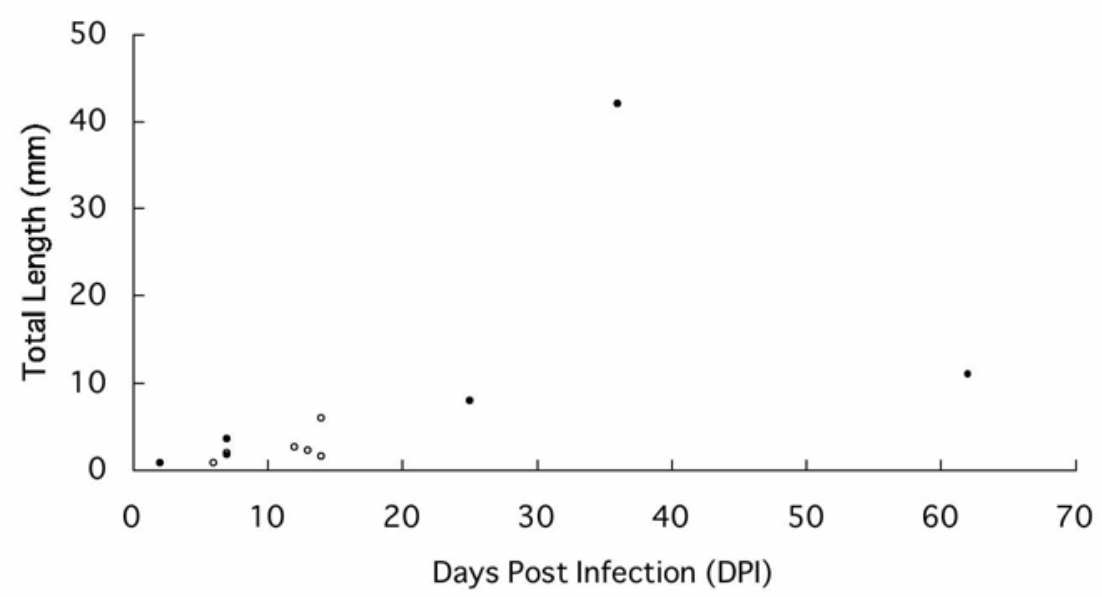

Fig. 4 Length of T. s. asiatica adult worm recovered from either gerbils (black circle) or hamsters (white circle) in the period of 2 to 62 days post-infection.

Development of tapeworms in human

Two out of the 3 human volunteers who took the cysticerci shed strobila or segments of $T$. $s$. asiatica in their feces. Strobilae with gravid segments and without scolex were found on day 64 (1 strobila), 90 (3 strobilae) and 131 (1 strobila) post-infection from the volunteer A and on day 114 (2 strobilae), 138 (1 strobila) and 194 (1 strobila) post-infection from the volunteer B. Volunteer C did not shed any proglottids and was deemed not to be infected. The prepatent periods of T. s. asiatica infection in the 2 human volunteers were 64 and 114 days respectively. The two human volunteers were dewormed using atabrine at days 191 (expulsion of 3 strobilae) and 194 (expulsion of 1 strobila) post-infection, respectively. Gravid segment excretion of volunteer A was found from 81 to 90 (mean: 4.3 proglottids per day; ranging from 0 to 14) and from 177 to 190 (mean: 9 proglottids per day; ranging from 0 to 42) days post-infection. Volunteer B excreted gravid segments from 169 to 191 days (5.3 proglottids per day; ranged from 0 to 33) post-infection. Eggs were detected during and after the period of segment shedding in the feces.

\section{Discussion}

It has been reported that oral inoculation with eggs of $T$. s. asiatica could not produce a successful infection in mice and that only intraperitoneal inoculation of oncospheres that have been hatched in vitro could result in a high recovery rate of metacestodes from SCID mice (Ito et al. 1997a; Ito and Ito 1999). However, our results showed that only a few metacestodes could be recovered from the intraperitoneally inoculated animals and the recovery rate was much lower than the subcutaneously inoculated ones.

Metacestodes of T. s. asiatica had been found to develop to maturity in the liver of 
experimentally infected pigs, showing hooklets and active movement at 28 DPI (Fan 1988). In SCID mice, T. s. asiatica metacestodes had been reported to develop to cysticerci with a total length (after the evagination) of 16 and $31 \mathrm{~mm}$, and with suckers diameter of 199 and $252 \mu \mathrm{m}$ at 9 and 25 weeks after subcutaneous inoculation, respectively (Wang et al. 2000). We observed a similar increase in the total length of cysticerci, but the diameter of suckers was larger than those reported by Wang et al. (2000). However, they also reported that the inner hooklets ranged from 11 to 19 and the outer hooklets are small and numerous on the rostellum of the 9 to 31 week-old cysticerci in addition to the numerous calcareous corpuscles in the neck region of the 9 week-old cysticerci (Wang et al. 2000). No further study on the differences of the number of the hooklets and calcareous corpuscles among the various ages of metacestodes had been published. In our study, the rudimentary hooks, that were reported to be inner hooklets by Eom and Rim (1993) and Fan et al. (1995), were observed in most but not all of the cysticerci of all the ages. We observed many small-granules aggregates in place of those outer hooklets as reported by Eom and Rim (1993) and Fan et al. (1995) in the rostellar region, with few calcareous corpuscles in the 10 week-old cysticerci. In the 24 week-old cysticerci, we observed only few small-granules aggregates in the rostellar region but abundant calcareous corpuscles. We also demonstrated that the infectivity of the cysticerci recovered from SCID mice varied with age by using the alternative definitive host models. No adult tapeworm could be recovered from the alternative definitive hosts (gerbils) inoculated with 10 week-old cysticerci, but several adult worms were recovered from the gerbils and hamsters orally inoculated with 20, 21, 24 and 45 week-old cysticerci. This could be due to the insufficient development of the 10 week-old cysticerci, whereas the older cysticerci were sufficiently developed to grow to maturity. Since the 45 week-old cysticerci showed the highest recovery rate among the various age, they were thought to be more mature than the other younger cysticerci.

However, in our study animals inoculated with a higher dose of the 21 week-old cysticerci showed lower recovery rate than those inoculated with a lower dose of the 20 week-old cysticerci. It has been reported that golden hamsters inoculated with 20 cysticerci of T. solium showed a lower recovery rate than those inoculated with 10 cysticerci (Monroy-Ostria et al. 1993). The probability of competition for nutrient among the worms resulting in a high inoculation dose of cysticerci leading to a low recovery rate of adult worm should be considered.

Evagination of the cysticerci scolex in vitro by incubation with bile has been used for evaluating the viability of cysticerci (Peniche-Cardena 2002). Fan et al. (2000) showed that the evagination rate of the 9 week-old cysticerci recovered from SCID mice was 77\% after incubation in 100\% pig bile for 20 minutes at $37^{\circ} \mathrm{C}$. However, the infectivity of those cysticerci was not been demonstrated. In our study, a high evagination rate (88\%) was obtained for 10 week-old cysticerci but they were found not to be infective to gerbils. Thus, a high evagination rate of the cysticerci does not always indicate high infectivity of the cysticerci in its definitive hosts. However, the presence of abundant 
calcareous corpuscles in the scolex and the degree of rostellar development could be considered as important criteria for evaluating the infectivity of the cysticerci.

Tapeworm recovery of the positive groups (H1, H2, G2, G3, and G4 groups) was $6.2 \%$ (2/32) at 1 to $7 \mathrm{DPI}, 20.8 \%(5 / 24)$ at 8 to $14 \mathrm{DPI}, 8.5 \%$ (3/35) at 15 to $28 \mathrm{DPI}$ and $8.3 \%(2 / 24)$ at 29 to 62 DPI. The recovery rate of the latter phase (29 to $62 \mathrm{DPI}$ ) was not lower than that of the earlier phase (1 to $7 \mathrm{DPI}$ ). We hypothesize that tapeworm of T. s. asiatica could survive in the intestine of their hosts for a long period after their establishment there. Thus, a highly sensitive, reliable and quick detection method such as coproantigen ELISA test is needed to confirm the establishment and survival of the worms in the intestine of the alternative definitive hosts.

Proglottids were reportedly detected in one out of three human volunteers who had eaten 10 week-old cysticerci of $T$. s. asiatica obtained from the liver of an experimentally infected Freisian Holstein calf (Chao et al. 1988; Fan et al. 1987). The first gravid proglottid was found on day 122 post-infection (Chao et al. 1988). Korean male volunteer demonstrated that the first gravid proglottid of T. s. a. could be recovered from his feces 76 days after eating 5 cysticerci obtained from naturally infected domestic pigs (Eom and Rim 1992). In our study, first strobila shed with the feces was observed at 64 DPI in the female volunteer and 131 DPI in the male volunteer. Gravid proglottids were first observed at 81 in the former and 177 DPI in the latter. Thus, there is a variation in prepatent period of human T. s. asiatica infection, but further study on the sex of the host is needed.

In the alternative definitive host infection, genital primordia were observed in the posterior segments of the tapeworms recovered on day 36 and 62 post-infection. It was obvious that $T$. $s$. asiatica develop better in the human host than in the alternative definitive hosts. However, a longer infection period might be necessary for its development in the alternative definitive hosts. In this study, the alternative definitive models were shown to be effective in demonstrating the infectivity of the various ages of T. s. asiatica metacestodes.

Acknowledgements We thank the staff of the Laboratory of Parasitology, Graduate School of Veterinary Medicine, Hokkaido University for their technical support and suggestions. This work was supported in part by Grant-in Aid for Scientific Research from Japan Society for Promotion of Science and by grants from the Ministry of Health, Labor and Welfare, Japan.

\section{References}

Bowles J, McManus D P (1994) Genetic characterization of the Asian Taenia, a newly described taeniid cestode of humans. Am J Trop Med Hyg 50: 33-44.

Cadigan F, Santon J S, Tanticharoenyus P, Chaicumpa V (1967) The Lar Gibbon as definitive and 
intermediate host of Taenia solium. Med Res 53: 844.

Chao D, Chung W C, Wang M M, Fan P C (1988) Experimental infection in a human subject by a possibly undescribed species of Taenia in Taiwan. J Helminthol 62: 235-242.

Eom K S, Rim H J (1992) Experimental human infection with Asian Taenia saginata metacestodes obtained from naturally infected Korean domestic pigs. Korean J Parasitol 30: 21-24.

Eom K S, Rim H J (1993) Morphologic descriptions of Taenia asiatica sp. n. Korean J Parasitol 31: $1-6$.

Eom K S, Rim H J (2001) Epidemiological understanding of Taenia tapeworm infections with special reference to Taenia asiatica in Korea. Korean J Parasitol 39: 267-283.

Eom K S, Jeon H K, Kong Y, Hwang U W, Yang Y, Li X, Xu L, Feng Z, Pawlowski Z S, Rim H J (2002) Identification of Taenia asiatica in China: Molecular, morphological, and epidemiological analysis of a Luzhai isolate. J Parasitol 88: 758-764.

Fan P C, Chung W C, Chan C H, Wong M M, Wu C C, Hsu M C, Huang S H, Chen Y A (1987) Studies on taeniasis in Taiwan. 3. Experimental infection of Taiwan Taenia in domestic animals. Proceedings of the First Sino-American Symposium 1: 119-125.

Fan P C (1988) Taiwan Taenia and Taeniasis. Parasitol. Today 4: 86-88.

Fan P C, Lin C Y, Kosman M L, Kosin E (1989) Experimental infection of Indonesia Taenia (Samosir strain) in domestic animals. Int J Parasitol 19: 809-812.

Fan P C, Chung W C, Lin C Y, Wu C C (1990a) Experimental infection of Thailand Taenia (Chiengmai strain) in domestic animals. Int J Parasitol 20: 121-123.

Fan P C, Chung W C, Lin C Y, Wu C C (1990b) The effect of fasting on the treatment of taeniasis. Chinese J Parasitol 3: 93-95.

Fan P C, Soh C T, Kosin E (1990c) Pig as a favorable intermediate host of a possible new species of Taenia in Asia. Yonsei Rep Trop Med 21: 39-58.

Fan P C, Lin C Y, Chen L M (1992a) Experimental infection of Taenia saginata (Burma) in domestic animals with special reference on its morphological characteristics. Ann Trop Med Parasitol 86: 317-318.

Fan P C, Lin C Y, Chung W C (1992b) Experimental infection of Philippine Taenia in domestic animals. Int J Parasitol 22: 235-238.

Fan P C, Lin C Y, Chen C C, Chung W C (1995) Morphological description of Taenia saginata asiatica (Cyclophyllidea: Taeniidae) from man in Asia. J Helminthol 69: 299-303.

Fan P C (2000) Taeniasis and Taenia saginata asiatica in Asia. Chinese J Parasitol 13: 71-94.

Fan P C, Wang I C, Chung W C (2000) Determination on evagination and survival of cysticerci of Taenia saginata asiatica in bile of pig and normal saline. Chinese J Parasitol 13: 123-139.

Fan P C, Chung W C, Chen E R (2001) Parasitic infections among the aborigines in Taiwan with special emphasis on Taeniasis asiatica. Kaohsiung J Med Sci 17: 1-15. 
Ito A, Chung W C, Chen C C, Ito M, Endo S, Okamoto M, Fan P C (1997a) Human Taenia eggs develop into cysticerci in scid mice. Parasitology 114: 85-88.

Ito A, Ito M, Eom K S, Chung W C, Chen C C, Ma L, Endo S, Fan P C (1997b) In vitro hatched oncospheres of Asian Taenia from Korea and Taiwan develop into cysticerci in the peritoneal cavity of female scid (severe combined immunodeficiency) mice. Int J Parasitol 27: 631-633.

Ito A, Ito M (1999) Human Taenia in severe combined immunodeficiency (SCID) mice. Parasitol Today 15: 64-67.

Ito A, Nakao M, Wandra T (2003) Human taeniasis and cysticercosis in Asia. Lancet 362: 1918-1920.

Kamiya M, Sato H, Kitaoka M, Ishiwata K, Oku Y, Ito M, Gathura P, Cross J H (1990) Laboratory rodent models for the tapeworm-stage of Taenia saginata and other related taeniid species. Emerging problems in food borne parasitic zoonosis: impact on agriculture and public health. Proceedings of the 33rd SEAMEO TROPMED Regional Seminar, Chiang Mai, Thailand. 22: 262-267.

Maravilla P, Avila G, Cabrera V, Aguilar L, Flisser A (1998) Comparative development of Taenia solium in experimental models. J Parasitol 84: 882-886.

Monroy-Ostria A, Monroy-Ostria T J, Gomez G J, Hernandez M O (1993) Some studies on the experimental infection of golden hamsters with Taenia solium. Rev Lat.-Amer Microbial 35: 91-98.

Oi T (1915) Examination of the eggs of intestinal parasites in central Taiwan. J Formosan Med Assoc 154: 816-825.

Peniche-Cardena A, Dominguez-Alpizar J L, Sima-Alvarez R, Argaez-Rodriguez F, Fraser A, Craig P S, Rodriguez-Canul R (2002) Chemotherapy of porcine cysticercosis with albendazole sulphoxide. Vet Parasitol 108: 63-73.

Schmidt G D, Roberts L S (2000) Tapeworm. In: Gerald D. Schmidt \& Larry S, Roberts` Foundation of Parasitology. 6th Ed. McGraw-Hill Press Singapore pp. 333-338.

Simanjuntak G M, Margono S S, Okamoto M, Ito A (1997) Taeniasis/ cysticercosis in Indonesia as an emerging disease. Parasitol Today 13: 321-323.

Verster A (1971) Preliminary report on the golden hamster as a definitive host of Taenia solium Linneaus, 1758 and Taenia saginata Goeze, 1782. J Vet Res 38: 63-64.

Verster A (1974) The golden hamster as a definitive host of Taenia solium and Taenia saginata. Onderstepoort J Vet Res 41: 23-28.

Wang I C, Guo J X, Ma Y X, Chung W C, Lu S C, Fan P C (1999) Sexual development of Taenia solium in hamsters from rodent-derived cysticerci. J Helminthol 73: 347-350.

Wang I C, Chung W C, Lu S C, Fan P C (2000) Rodent model for long-term maintenance and development of the viable cysticerci of Taenia saginata asiatica. Korean J Parasitol 38: 
237-244.

Zhang L, Hao H, Zhang B, Wang H, Wang Y, Li Z, Yang H, Li Y, Wu Y (1999) First discovery of Taenia saginata asiatica infection in Yunnan province. Chin J Parasitol Parasit Dis 17: 95-6. (In Chinese). 